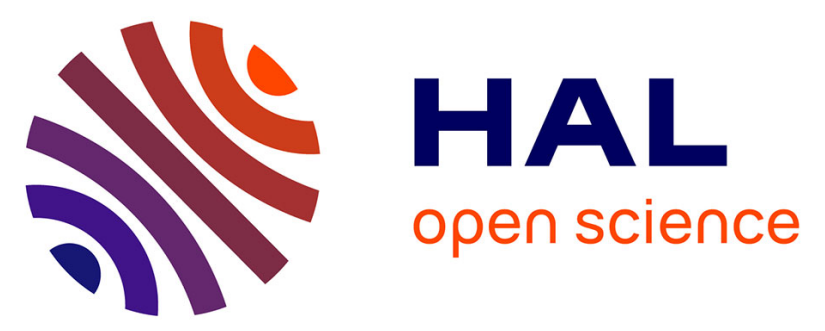

\title{
Terahertz, X-ray and neutron computed tomography of an Eighteenth Dynasty Egyptian sealed pottery
}

\author{
Emmanuel Abraham, Maryelle Bessou, Anne Ziéglé, M.-C. Hervé, L.
}

Szentmiklósi, Z. S. Kasztovszky, Z. Kis, M. Menu

\section{To cite this version:}

Emmanuel Abraham, Maryelle Bessou, Anne Ziéglé, M.-C. Hervé, L. Szentmiklósi, et al.. Terahertz, X-ray and neutron computed tomography of an Eighteenth Dynasty Egyptian sealed pottery. Applied physics. A, Materials science \& processing, 2014, 117 (3), pp.963-972. 10.1007/s00339-014-8779-3 . hal-01094435

\section{HAL Id: hal-01094435 \\ https://hal.science/hal-01094435}

Submitted on 19 Feb 2016

HAL is a multi-disciplinary open access archive for the deposit and dissemination of scientific research documents, whether they are published or not. The documents may come from teaching and research institutions in France or abroad, or from public or private research centers.
L'archive ouverte pluridisciplinaire HAL, est destinée au dépôt et à la diffusion de documents scientifiques de niveau recherche, publiés ou non, émanant des établissements d'enseignement et de recherche français ou étrangers, des laboratoires publics ou privés.

\section{다(1)(2)}

Distributed under a Creative Commons Attribution - ShareAlikel 4.0 International 


\section{Terahertz, X-ray and neutron computed tomography of an Eighteenth Dynasty Egyptian sealed pottery}

\author{
E. Abraham • M. Bessou • A. Ziéglé • \\ M.-C. Hervé • L. Szentmiklósi · Z. S. Kasztovszky • \\ Z. Kis $\cdot$ M. Menu
}

\section{Introduction}

Forever, art scientists, historians and curators are interested in the precise determination of the material composition and substructure analysis of historic objects. This scientific approach is essential as it can be employed to reveal the history of the sample, investigate the original material properties and even discover how the object has been restored in the past centuries.

Imaging with X-rays and neutrons is powerful for the investigation of a large variety of materials. Radiography belongs to the family of direct imaging techniques, where the visual representation of an object is obtained by detecting the modification of an incident beam as it passes through the matter. Radiography provides a two-dimensional (2D) projection while tomography allows visualizing the inner volume of a three-dimensional (3D) sample [1]. $\mathrm{X}$-ray imaging is routinely used to analyze museum artifacts. In the field of Egyptology, it has been applied to paintings, sculptures, sarcophagus and mummies analysis [2]. It is considered as an efficient technique with submillimeter spatial resolution. It provides contrasted images depending on the radiodensity of the materials [3]. However, X-rays are sometimes not recommended regarding to the ionizing power of the radiation and the difficulty of sample thermoluminescence dating after irradiation [4]. Radiography also requires strict safety rules based on the knowledge of the radiation effects and on the principles of protection.

Nowadays, more than 65 years after the pilot experiments in neutron radiography by Kallman in 1947, neutron imaging techniques are available as efficient tools of nondestructive testing in cultural heritage science. Neutron radiography or tomography [5] is often applied to visualize the internal structure $[6,7]$ of the object even if it is

Centre de Recherche et de Restauration des Musées de France,

Palais du Louvre, Paris, France 
embedded in a block of soil to verify its integrity, assess the need of conservation and reveal restoration patches and manufacturing techniques. Neutrons can penetrate deep into the material so that bulky samples can be successfully analyzed. The contrast depends on the probabilities of nuclear interactions. The spatial resolution of neutron imaging is generally worse than that of X-ray imaging due to the properties of the neutron beams and detection techniques. Routinely $100200 \mu \mathrm{m}$, in state-of-the-art setups $2040 \mu \mathrm{m}$ resolution is achievable. Neutron imaging is considered to be a fully nondestructive technique, although the irradiation may create transitional activation of the sample that usually decays within a few days of cooling time.

Terahertz (THz) radiation has recently emerged as a possible powerful candidate in the field of art conservation for the investigation of various art-related materials [8]. Being nondestructive and contactless in nature, this radiation (wavelengths from $30 \mu \mathrm{m}$ to $3 \mathrm{~mm}$ ) can penetrate into non-conductive and nonpolar materials and offers complementary spectroscopic data for a better diagnosis and understanding of artworks. In Egyptology, $\mathrm{THz}$ imaging has been used for the analysis of an ancient Egyptian mummy [9], written papyrus [10] and clay artifacts [11]. Fukunaga et al. [12] reported the first use of $\mathrm{THz}$ timedomain reflection imaging for the analysis of textiles of an Egyptian human mummy preserved at the Metropolitan Museum of Art (New York). They pointed out the difficulty of conventional X-rays to visualize the bandages due to the low radiological contrast of the fabric layers. For the first time to our knowledge, we present in this paper a comparative study applied to an art-related object using $\mathrm{THz}, \mathrm{X}$-ray and neutron imaging.

\section{A case study}

In 1861, Dr. Jean Ernest Godard (Cognac, 1826 Jaffa, 1862) was entrusted with a mission in Egypt by the French Minister Alexandre Walewski, during the reign of emperor Napoleon III. He bought many objects in Louqsor and Cairo between September and November 1861. Today, these items are stored in the Museum of Aquitaine in Bordeaux (France). In his diary, Dr. Godard does not mention the precise circumstances of these acquisitions. However, this document reveals the origin of over 300 pieces, mostly found in pharaoh's graves [13]. In the framework of the CHARISMA project (Cultural Heritage Advanced Research Infrastructures, Synergy for a Multidisciplinary Approach to Conservation/Restoration), the object under study in this paper is a small bottle made of red clay, without any decoration (Fig. 1). It is $97 \mathrm{~mm}$ high with a maximum diameter of $64 \mathrm{~mm}$. It bears a

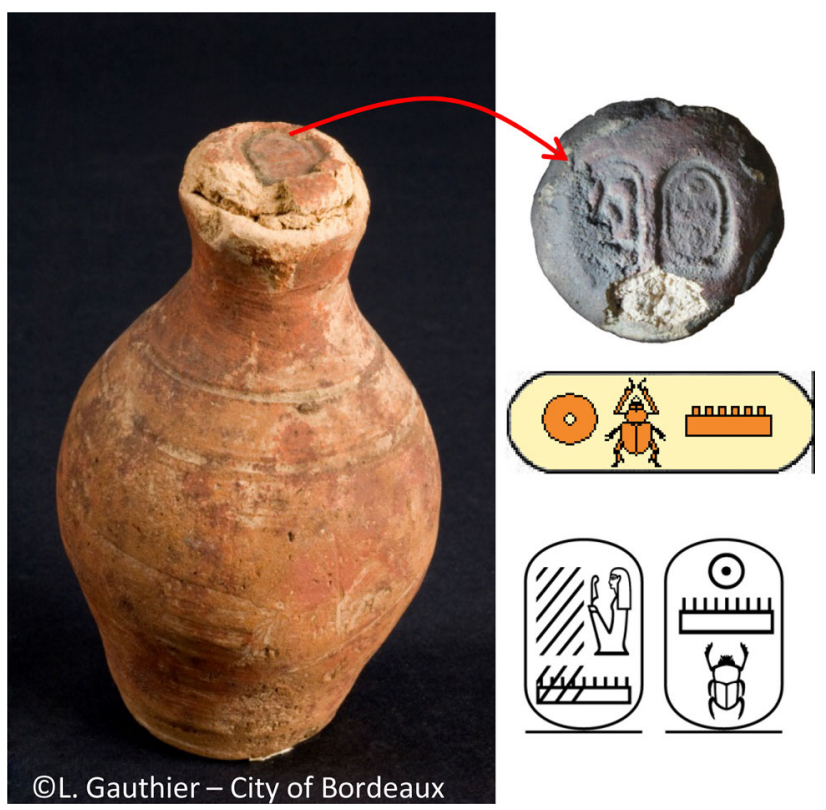

Fig. 1 Photograph of the Egyptian pottery (Museum of Aquitaine, inventory number 8608) and details of the seal with the cartouche of Menkheperre Tuthmosis III's, pharaoh of the Eighteenth Dynasty (1479 1425 B.C.)

hieroglyphic seal on its cap, identified as the Menkheperre Tuthmosis III's cartouche. This pharaoh is a well-known member of the Eighteenth Dynasty (XVth c. BC), including Tutankhamun, Akhenaton and the queen Hatshepsut. He ascended the throne as a child until he died in 1450 BC. He was buried in the Valley of the Kings, but his tomb was pillaged by grave robbers. Nevertheless, his mummy was found in 1881 in a royal cache and rests today in the Cairo Museum. The object under study may be of some importance, directly linked with the funeral ritual of this pharaoh. This is not a canopy vase, containing viscera of the dead body. Most likely, it is in relationship with the offerings of food to the dead during the pharaoh's funerals.

The main purpose of our study is to investigate the artifact using computed tomography (CT) of various modalities in order to analyze both the bottle itself and its content. This has been performed using three different but complementary techniques. In a few previous studies, the simultaneous use of X-rays and neutron imaging for cultural heritage objects was already exploited, but the potential of $\mathrm{THz}$ imaging for this purpose has never been jointly investigated. In our study, THz radiation has been first employed in the museum since the $\mathrm{THz}$ scanner is portable and presents any specific safety rules for the users [14]. Then, the object has been transferred to a hospital to be analyzed by X-ray scanner. Finally, we used the unique neutron beam facility available at the Budapest Neutron Centre. 


\section{Experimental methods}

For 3D visualization of a sample, many tomographic techniques already exist such as single photon emission and X-ray CT, optical coherence tomography, nuclear magnetic resonance tomography, ocean acoustic tomography, positron emission tomography, transmission electron microscopy and computed medical imaging [15]. Tomography involves gathering a set of projection data taken at multiple directions and the subsequent use of tomographic reconstruction software. Imaging methods are generally based on the detection of the transmitted radiation through a defined medium by sensitive detectors. The radiation beam is attenuated differently (absorption, scattering, diffraction, etc.) by the composition elements of the sample giving contrast variations in the recorded radiography image. This attenuation can be expressed by [16]:

$I(x, y)=I_{0}(x, y) \exp \left[-\int_{\text {path }} \mu(x, y, z) d z\right]$,

where $I_{0}(x, y)$ and $I(x, y)$ are, respectively, the intensities of the incident and transmitted beam in a plane $(x, y)$ transversal to the propagation direction $z$, and $\mu(x, y, z)$ is the attenuation coefficient in the sample.

\section{1 $\mathrm{THz}$ imaging instrumentation}

THz CT is analogous to X-ray CT and uses the same principles and reconstruction algorithms. However, as mentioned in the introduction, the main advantage of $\mathrm{THz}$ $\mathrm{CT}$ is the possibility to perform on-site noninvasive and nondestructive imaging, compared with X-ray CT which requires strict safety rules based on the knowledge of the radiation effects and on the principles of protection. In such case, $\mathrm{THz}$ CT can be used as an alternative technique to visualize $3 \mathrm{D}$ objects.

The interaction of $\mathrm{THz}$ waves with matter involves only low-energy excitations since a radiation centered at $1 \mathrm{THz}$ corresponds to a photon energy of $4 \mathrm{meV}$. These excitations correspond for instance to intraband transitions in semiconductor nanostructures, phonon modes in organic and inorganic crystals, rotation vibration transitions in molecules and collective large-amplitude motions in biomolecules. Consequently, the physical nature of the attenuation coefficient $\mu(x, y, z)$ involved in $\mathrm{THz}$ imaging will be completely different from that one of X-ray or neutron imaging. $\mathrm{THz}$ spectroscopy has been for instance successfully applied to the detection of drugs or explosives [17]. Shortly, as previously mentioned, $\mathrm{THz}$ radiation will be strongly attenuated by any polar and conductive materials (water and metals), whereas it will be more easily transmitted by ceramics, plastics, wood, organic pigments and papers, which can be very effective for diagnosis in art conservation.
Recently, we developed a THz CT system based on a millimeter continuous wave source coupled with an infrared thermal sensor. Especially, this device has been used for THz CT of opaque objects [18], which has been first demonstrated in 2002 [19]. The CT method makes it possible to obtain cross-sectional images by measuring the transmitted amplitude of the $\mathrm{THz}$ wave at multiple projection angles. Although THz CT seems powerful, most of published results concerned the investigation of simple manufactured phantom objects such as foam or polyethylene cylinders, drilled with metallic bars [18] or filled with specific chemical substances such as glucose or lactose powder [20]. The main reason is the limitation coming from the diffraction effects and Fresnel losses experienced by the propagation of the $\mathrm{THz}$ wave through the sample.

The millimeter wave CT scanner (shortly called ' $\mathrm{THz}$ scanner') is based on a compact millimeter wave Gunn diode $(110 \mathrm{GHz}, 20 \mathrm{~mW})$ coupled with a horn antenna (Fig. 2). The output beam is collimated using an off-axis parabolic mirror $\left(f_{0}=150 \mathrm{~mm}\right)$ and then focused with a Teflon lens $\left(f_{0}=60 \mathrm{~mm}\right)$ on the sample, which is positioned on three-axes XY- $\theta$ motorized stages. The angle $\theta$ corresponds to a rotation around the vertical $\mathrm{Y}$-axis. The spatial resolution of the $\mathrm{THz}$ scanner is limited to a few millimeters owing to the long wavelength of the emitting source. Symmetrically, the focal volume is imaged using a similar arrangement on a commercial pyroelectric sensor (Spectrum Detector Inc.). For final data acquisition, the $\mathrm{THz}$ beam is modulated at $20 \mathrm{~Hz}$ by an optical chopper and the amplitude of the transmitted $\mathrm{THz}$ is acquired with a lock-in amplifier. A 2D transmission image of the sample is obtained by moving the object in the $\mathrm{X}$ and $\mathrm{Y}$ directions with a scan step of $1 \mathrm{~mm}$ in both directions. With a scan speed of 5 pixels/sec, the acquisition time for a $100 \times 100$ pixels 2D image size is about $30 \mathrm{~min}$. For $3 \mathrm{D}$ reconstruction, the sample is rotated in order to provide a different visualization of the object. From these tilted series, we are able to construct the sinogram of the object which represents, for a given horizontal slice, the evolution of the transmitted $\mathrm{THz}$ amplitude as a function of the rotation angle. Here, to get a reasonable acquisition time for 3D imaging, we selected a rotation step of $10^{\circ}$. In this case, we obtained the corresponding 18 projections in nearly $9 \mathrm{~h}$. Despite this long acquisition time, which is generally not a problem for most artifact imaging, we should insist that the $\mathrm{THz}$ scanner offers the advantage of low cost $(<20 \mathrm{k} €)$ and, as already mentioned, on-site imaging without any safety procedures.

This limited number of projections induces another important limitation for THz CT compared with X-ray CT. The back projection of the filtered projections is employed for $3 \mathrm{D}$ reconstruction [21]. This reconstruction process is based on the inverse Radon transform, which computes the 

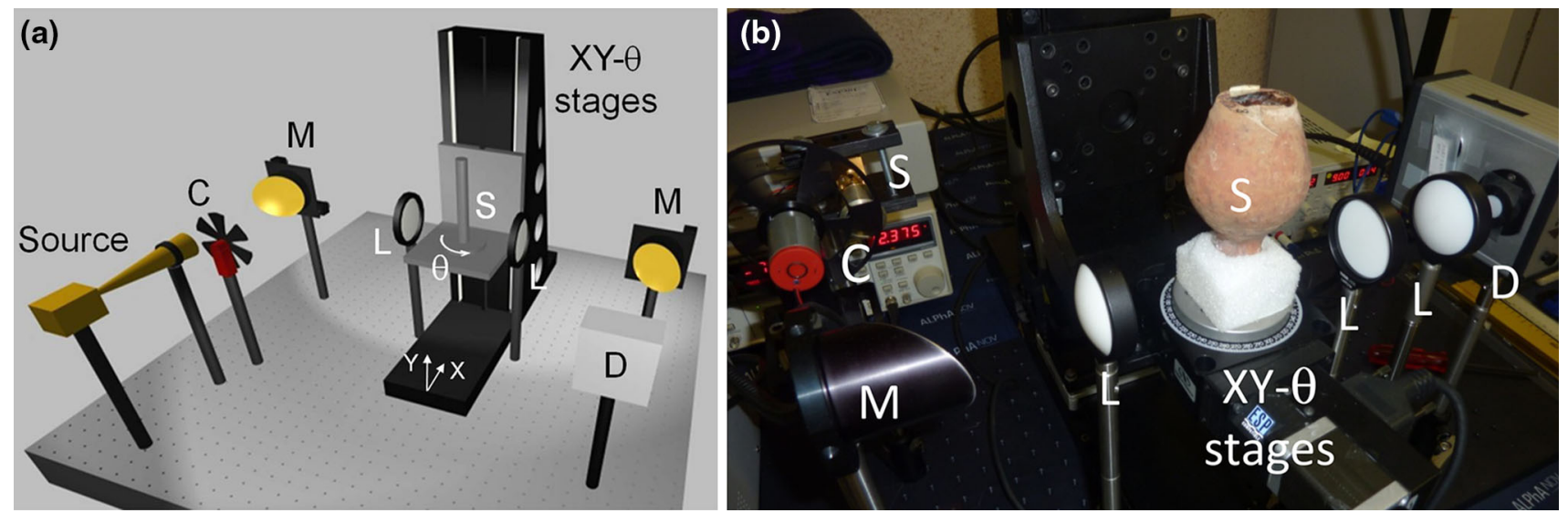

Fig. $2 \mathrm{THz}$ CT. a Schematic view of the setup. $C$ chopper, $M$ parabolic mirror, $L$ Teflon lens, $S$ sample, $D$ pyroelectric detector. b The THz scanner analyzing the Egyptian pottery in the Museum of Aquitaine (the second parabolic mirror has been replaced by a Teflon lens)
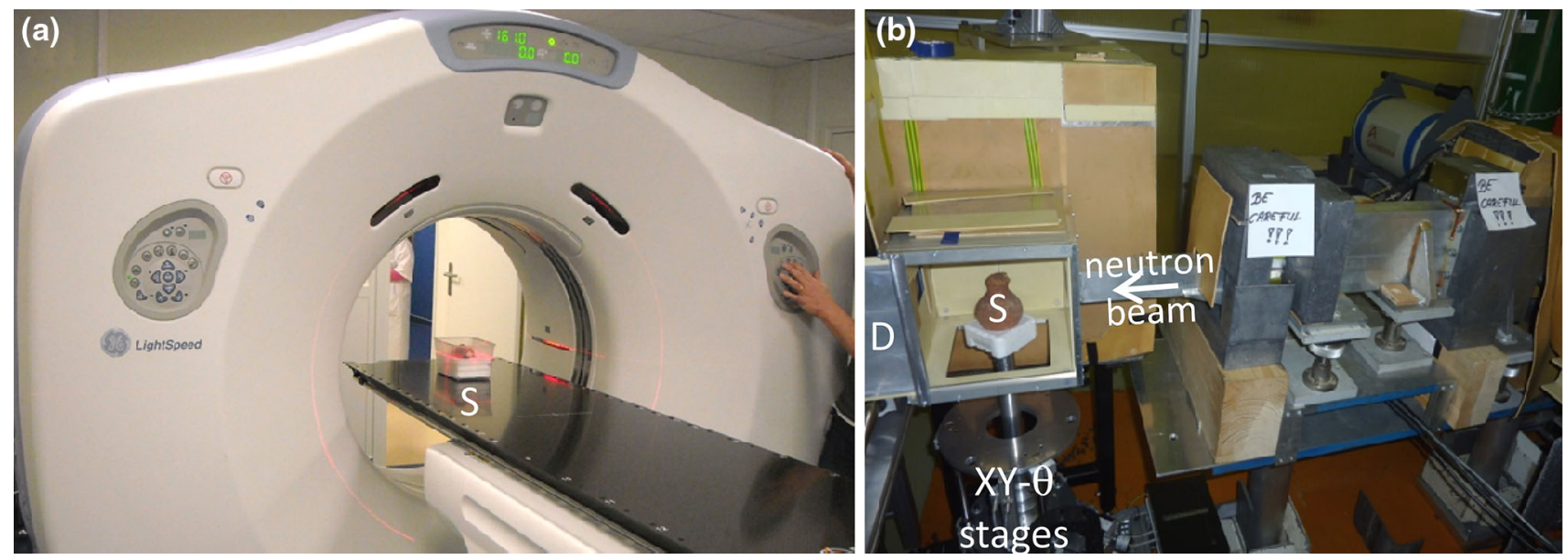

Fig. 3 a X ray CT at the Haut Lévêque Hospital. b Neutron CT at the Budapest Neutron Centre. $S$ sample, $D$ detector

final pixel values from the filtered projections. It is widely developed in X-ray CT scan imaging and also commonly used in $\mathrm{THz}$ CT since it is proposed in most of CT software tools.

\subsection{X-ray imaging}

$\mathrm{X}$-ray imaging method is based on the interaction of X-rays (energy from ten to several hundreds $\mathrm{keV}$ ) with the charge distribution of the electron shell. Therefore, the X-ray attenuation coefficient $\mu(x, y, z)$ increases exponentially with the atomic number of the elements, i.e., with the number of electrons. This means that X-ray radiography will be very sensitive to this atomic number with high transmission through materials composed by light atomic elements and strong attenuation through materials composed by heavier ones such as metals [16]. X-ray CT can visualize dense materials such as wood, bones and biological tissues but cannot be easily applied to soft materials such as plastics, papers or paintings [22].
For our investigation, we used the X-ray CT scanner installed in the radiotherapy centre of the Haut-Lévêque Hospital in Bordeaux, in the service of Mrs. R. Trouette, M. Montaudon and J.B. Boutolleau. The scanner is a LightSpeed RT 16 by GE Healthcare [23] (Fig. 3a). It is a third-generation multi-slice helical CT scanner, featuring a $53 \mathrm{~kW}$ generator power, a 6.3 MHU tube (anode heat capacity) and a fastest gantry rotation time of $0.5 \mathrm{~s}$. It is capable of imaging 16 slices per rotation. The image reconstruction technique for helical scanning uses GE's CrossBeam $^{\mathrm{TM}}$ and HyperPlane ${ }^{\mathrm{TM}}$ algorithms, which are developments of the ASSR (adaptive single slice re-binning) technique. The instrument is fixed so that the object had to be transported from the museum to the hospital. For our study, scan parameters were fixed to $140 \mathrm{kV}$ and $200 \mathrm{~mA}$. Image reconstruction was achieved with the socalled 'Detail' mathematical filter offering trade-offs between spatial resolution, imaging contrast and noise. It was selected in order to enhance the visibility of lowcontrasted details, in spite of an increased noise in the 
image. Spatial resolution was about $0.2 \mathrm{~mm}$ with this setting. From these settings, the grayscale $\mathrm{X}$-ray image can be visualized differently by adjusting the window width (W) and level (L). Details with pixel values out of the window settings will be displayed as either black or white.

\subsection{Imaging and element analysis with neutrons}

Imaging with neutrons was conducted at the Budapest Neutron Centre (Hungary). The instrument is driven by the Budapest Research Reactor (BRR) which is a tank type, light water moderated and cooled, Russian type research reactor with $10 \mathrm{MW}$ thermal power. BRR as a high flux neutron source has been utilized for basic and applied research. Clearly, this kind of neutron imaging is offered by huge and extremely costly instruments available in a few places in the world. However, in many of these neutron centers, user programs are operated to facilitate the access of such instrumentation.

With this method, the slow (i.e., thermal or cold) neutron beam (energy in the order of meV) interacts with the atomic nucleus. The neutron attenuation coefficient $\mu(x, y$, $z$ ) is dependent on the coherent and incoherent scattering and absorption cross sections. It does not show a systematic dependence from the atomic number of the elements [16]. As a result, neutron imaging is very sensitive to elements such as $\mathrm{H}$ and $\mathrm{B}$, where $\mathrm{X}$-rays do not provide a sufficient contrast, as previously explained. Neutrons can also easily penetrate thick layers of metals such as $\mathrm{Pb}, \mathrm{Fe}$ and $\mathrm{Cu}$ where X-rays with energies of several hundreds $\mathrm{keV}$ fail. At last, since the attenuation coefficient $\mu(x, y, z)$ fluctuates with the atomic number, neutron radiography can discriminate neighboring elements contrary to X-rays.

The experimental setup of interest is the neutron-induced prompt gamma spectrometer (NIPS) for element analysis, integrated with neutron optics and radiography for material analysis (NORMA) facility, specially designed for cold neutron tomography (Fig. 3b) [24]. The facility is located at the end of the neutron guide No 1 . in the Cold Neutron Source Hall. From the end of the neutron guide, the cold neutron beam arrives through a flight tube of $40 \times 40 \mathrm{~mm}^{2}$ cross section to the sample chamber. An n-type coaxial HPGe detector (Canberra GR 2318/S) equipped with a Scionix BGO Compton suppressor is used for the prompt gamma measurements. The passive gamma shielding is made of standard lead bricks with low Sb content covered from outside with a ${ }^{6} \mathrm{Li}$ plastic neutron absorber layer. A digital signal processor is connected to an Ethernet-based multichannel analyzer module (Canberra AIM 556B) to collect the counts. The NORMA setup consists of a $100-\mu \mathrm{m}$-thick ${ }^{6} \mathrm{Li} / \mathrm{ZnS}$ scintillator, a quartz mirror with $\mathrm{Al}$ layer and a cooled, black-and-white, back-illuminated Andor iKon-M CCD camera with 1,024 × 1,024 pixels and 16-bit pixel depth. The custom optics projects a $48.6 \times 48.6 \mathrm{~mm}^{2}$ area onto the $13 \times 13 \mathrm{~mm}^{2}$ sensitive surface of the CCD chip. The resolution of the imaging system falls between 220 and $500 \mu \mathrm{m}$, depending on the sample's distance to the neutron sensitive screen.

The imaging acquisition software Andor SOLIS was applied to record images in external triggering mode. The radiographic projections (601 images) were taken with the full neutron beam, at every $0.3^{\circ}$ increment through a $180^{\circ}$ rotation. The radiography images were corrected for the spatial inhomogeneity of the beam and the thermal noise of the camera. For tomographic imaging, the reconstruction code OCTOPUS 8.6 was used, that relies on the inverse Radon transformation and filtered back-projection algorithms [21]. The visualization of the dataset in 3D space (volume rendering) was carried out using VGStudio 2.1.

Another unique feature offered by the NIPS-NORMA instrument is to perform a combination of neutron imaging with prompt gamma activation analysis of the material inside the jar. Revealing the inner structure by imaging the time-consuming elemental analysis is only carried out for parts with interesting features. The method is called NR/ NT-driven prompt gamma activation imaging (PGAI) [24]. Using a $10 \times 10 \mathrm{~mm}^{2}$ collimated neutron beam with a thermal equivalent flux of $2.7 \times 10^{7} \mathrm{~cm}^{-2} \mathrm{sec}^{-1}$, the composition of selected parts has been analyzed and semiquantitative element identification was provided. The acquisition time for each point of the PGAI measurement has been set to $60,000 \mathrm{~s}$. As neutrons traversing through the whole body of the jar irradiate a chord-like volume, including the wall, it needs special measurement arrangement to analyze only the inner content from one single measurement. Unfortunately, collimating both the beam and the solid angle of the gamma detection would have highly increased the acquisition time. Therefore, an irradiation of the inner content together with the jar wall, as well as an irradiation of a part without filling material, was performed separately. The difference between the two measurements can provide the element composition for the inner content of the jar. Additionally, the composition of the cork has also been determined similarly.

\section{Results}

\section{1 $\mathrm{THz}$ imaging}

Figure $4 \mathrm{a}$ and $\mathrm{b}$ presents the $2 \mathrm{D} \mathrm{THz}$ transmission images of the pottery on the horizontal and vertical (turned upsidedown) positions, respectively. These correspond to the front views of the object. The white color indicates a lower $\mathrm{THz}$ transmission. These positions have been selected in order to determine the presence and mobility of an eventual 

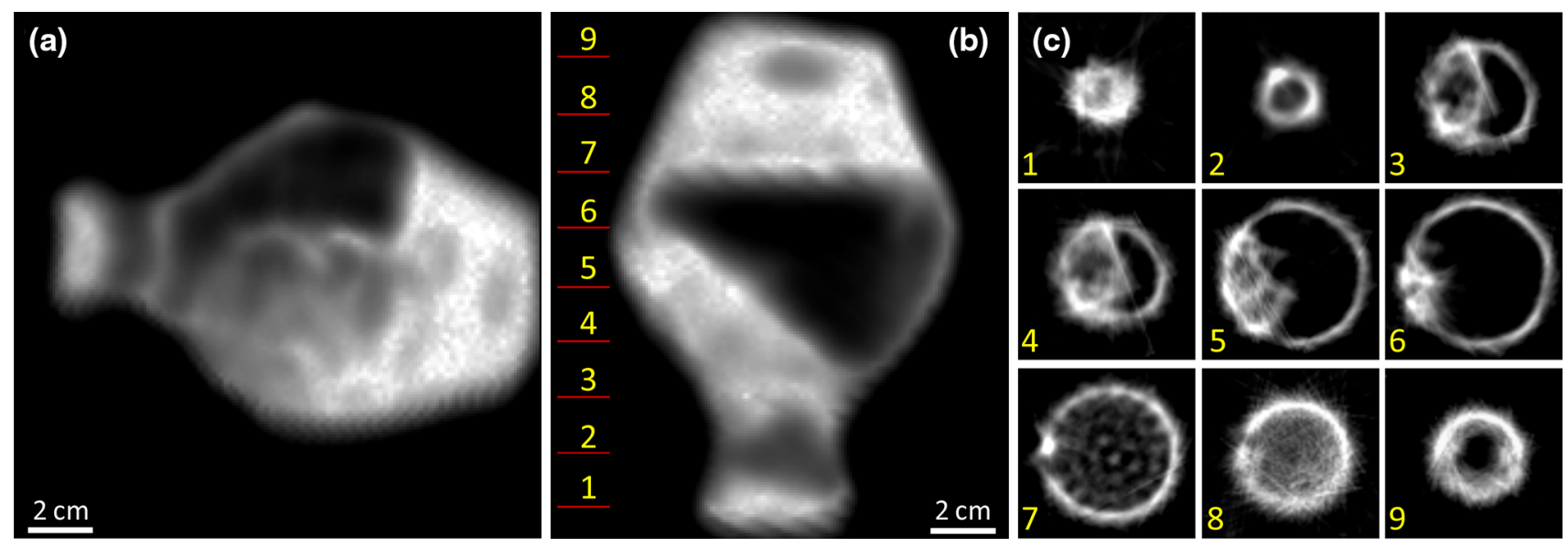

Fig. $4 \mathrm{THz}$ CT. a Front view, horizontal position. b Front view, upside down vertical position. c Axial views at the position indicated in (b). Online Resource 1 is a 3D video of THz CT
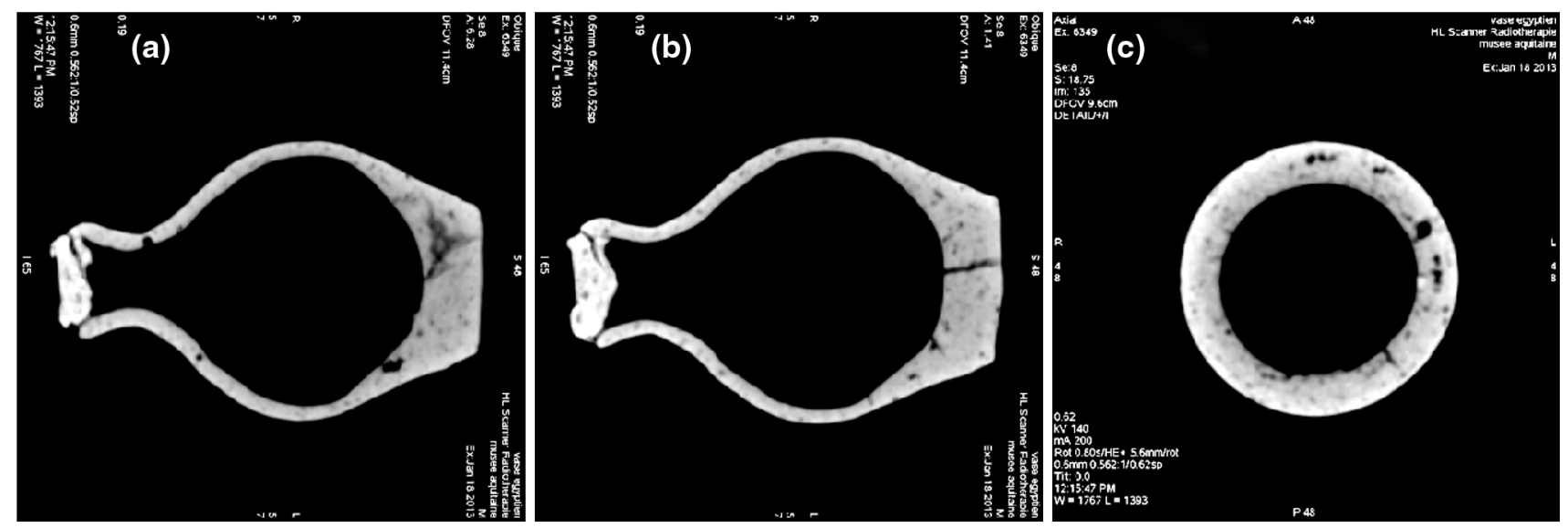

Fig. 5 X ray CT (140 kV $200 \mathrm{~mA})$. Window settings: $W$

1767,

internal content. Both images reveal two areas of low $\mathrm{THz}$ transmission, one near the bottom and another one inside the internal cavity whose localization depends on the pottery position. $\mathrm{THz}$ absorbance in these zones has been evaluated to 3.4 (bottom) and 3 (inside). We can conclude that the material absorbing the $\mathrm{THz}$ wave in the first area is fixed since it does not move depending on the bottle's position, whereas the one from the second area is mobile and deformable since its shape can fit the inner contour of the pottery.

We then performed a CT analysis of the object. The tomography has been completed by rotating the object in a turned upside-down position around the vertical axis. From the projection data, we were able to get the axial views of the pottery. Figure $4 c$ represents nine of these axial views whose positions are also referred in Fig. 4b. These views clearly show the areas where the $\mathrm{THz}$ radiation is absorbed within the pottery. A $3 \mathrm{D}$ video recording of the THz CT is also available in Online Resource 1. From the reconstruction, the internal volume of the bottle has been estimated to
1,393. a Front view 1. b Front view 2. c Axial view

$100 \mathrm{~cm}^{3}$ with about $25 \mathrm{~cm}^{3}$ filled by the mobile content. Concerning the bottom of the pottery where $\mathrm{THz}$ radiation is strongly absorbed, we can conclude at the present stage that either the bottle is filled by a fixed content in this part; either the thickness of the pottery walls is larger in this region so that $\mathrm{THz}$ radiation is not transmitted. It is also important to notice that, using a broadband $\mathrm{THz}$ source associated with a THz time-dependent spectrometer [25], it should be possible to get additional information about the object such as the chemical nature of content, even if the spectral fingerprints of complex molecules is still challenging.

\subsection{X-ray imaging}

After on-site $\mathrm{THz}$ analysis performed in the Museum of Aquitaine, the pottery has been moved to the Haut-Lévêque Hospital for X-ray CT examination. First, the window settings have been set to $W=1,767$ and $L=1,393$. Figure $5 \mathrm{a}$ and $\mathrm{b}$ is the corresponding front views, showing that, with these settings, only the walls are visible, 

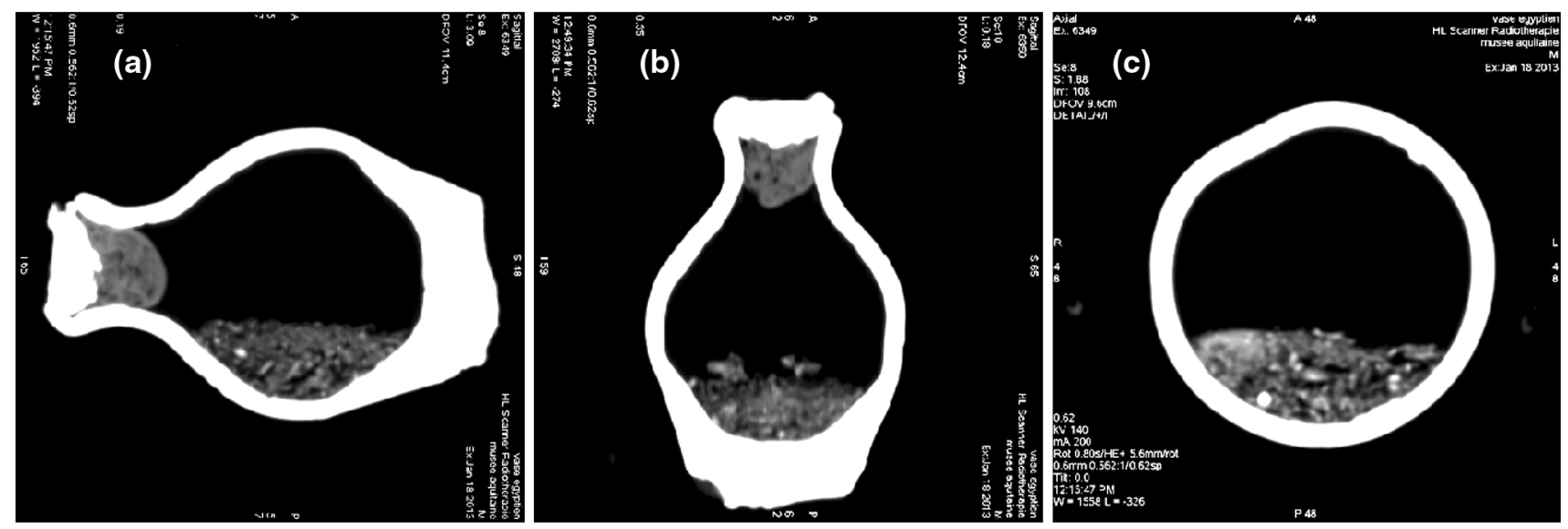

Fig. $6 \mathrm{X}$ ray CT $(140 \mathrm{kV} 200 \mathrm{~mA})$. a Front view 1, window settings: $W \quad$ 1,952, $L$

$L \quad 274$. c Axial view, window settings: $W \quad 1,558, L \quad 326$

indicating that the content is composed of a low-contrasted material for X-rays. Here again, the white color indicates a lower transmission of X-rays. We can see that the bottle presents important cracks in the bottom and also inside the walls. This is also visible on the axial view represented in Fig. 5c. This was not visible at all with $\mathrm{THz}$ CT owing to the poor spatial resolution. Another important feature is that the low $\mathrm{THz}$ transmission obtained on the bottom of the bottle is not due to the presence of a fixed absorbing content but rather due to the bottle shape itself which presents a thick bottom.

Then, the window level has been set to negative values to enhance the representation of low-contrasted materials. With this setting, as seen in Fig. 6, the visualization of the red clay is completely saturated in the image, whereas the content can be analyzed. Front and axial views clearly reveal the presence of the mobile and deformable content, previously discovered by $\mathrm{THz} \mathrm{CT}$. Here, the higher spatial resolution makes it possible to see that the content is inhomogeneous with small and bigger fragments. It is not composed of mineral materials since its density is much lower than the pottery walls made of clay. The front views also reveal that the cork consists of two parts with a superior sealing in clay (saturated white color) and inferior one made of an unknown low-contrasted material (gray color). The density of the internal cork is quite homogeneous even if some black spots can be observed. Also its chemical nature is very different from red clay since the radiography shows a higher transmission through the cork compared with red clay.

To summarize, Fig. 7 presents a 3D image of the pottery obtained with a volume rendering software, where the localizations and volumes of the different representative elements have been mentioned. A 3D video recording of $\mathrm{X}$-ray CT is also available in Online Resource 2. We can notice that the previous estimation of the content volume

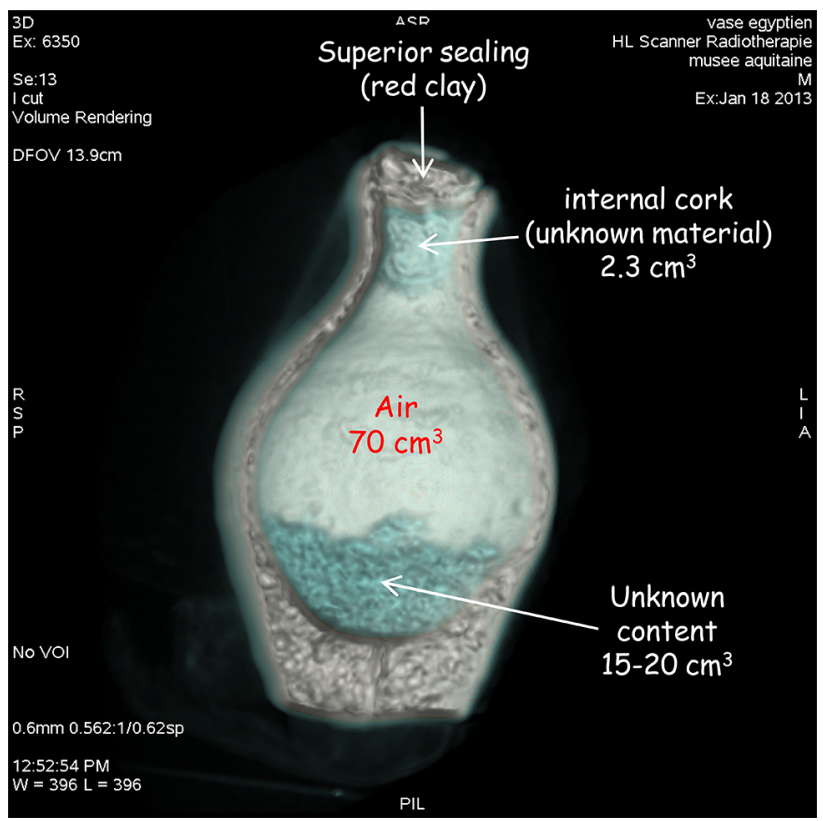

Fig. $7 \mathrm{X}$ ray CT summary. 3D representation of the pottery obtained with a volume rendering software. Representative materials have been mentioned together with their volume (also available as a 3D video in Online Resource 2)

measured with $\mathrm{THz} \mathrm{CT}\left(25 \mathrm{~cm}^{3}\right)$ is close to the more accurate value of $1520 \mathrm{~cm}^{3}$ obtained with X-ray CT.

\subsection{Neutron imaging}

The pottery was finally moved to Budapest in order to be illuminated by neutrons available at the Budapest Neutron Centre. Owing to the $40 \times 40 \mathrm{~mm}^{2}$ cross section of the neutron beam and the $97 \mathrm{~mm}$ height of the pottery, we created a composite front view of the whole jar from a set of nine partially overlapping tile images, by moving the object along the neutron beam (Fig. 8a). Again, the white 
color corresponds to a lower transmission of the neutron beam. The gray rectangle at the bottom of the image is the foam holder that has been used to fix the object. At first, we notice that the neutron image does not reveal the cracks and defaults in the pottery wall contrary to previous X-ray CT. This can be attributed to a lower imaging contrast in red clay with neutron compared with X-rays. This means that X-rays are more adapted to study the conservation state of the pottery itself. However, the neutron image can reveal finer details of the heterogeneous content. We note that the content is in an oblique position since the bottle was previously tilted in order to slightly separate the bottom of the bottle from its content. We can also observe that the internal cork is very smooth in its inferior part with again the certitude that it is not composed of red clay contrary to the superior sealing of the pottery. Then, the space occupied by the content has been studied by rotating the bottle around a vertical axis, as shown in Fig. 8b. From the $0^{\circ}, 30^{\circ}$ and $60^{\circ}$ front views, we can clearly see the displacement of the content and appreciate its general texture with the presence of small twigs of anything similar. Online Resource 3 shows also a 3D video representing the object fixed in another position with the inner content in a horizontal position.

We also focused our attention on the way the pottery has been sealed since we were surprised by the double sealing with the external red clay and the internal cork. Neutron CT has been performed specifically in the region of the cork. From these projections, we were able to reconstruct the 3D image of the cork, as shown in Fig. 9a. The external stopper made of clay is clearly visible with some cracks or damages in the periphery. These damages have been previously observed with X-rays (Fig. 5b). More surprising is the specific texture of the internal cork which presents a filament texture as if it is composed of a long string that has been arranged as a small ball. This is clearly confirmed by the axial views (Fig. 9b and c) obtained along the planes 1 and 2 in Fig. 9a. Figure 9b corresponds to the axial view of the pottery in the superior part of the internal cork, whereas Fig. $9 \mathrm{c}$ is the axial view in its inferior part. The external gray ring is the red clay of the pottery wall. Both front views confirm very distinctly that the internal cork is effectively composed by a long string that has been arranged as a ball to form a compact internal stopper under the external clay sealing. It probably concerns linen since this organic tissue was largely used in ancient Egypt. The complex arrangement of the ball string is even more visible in Online Resource 4 which is a 3D video of the cork using neutron CT.

In Table 1, we show the elemental compositions of three different parts of the jar, determined by PGAI. For this elemental analysis, the impacts of neutron beam are indicated by the red markers in Fig. 8a. The investigated parts are the following: (1) 'Full': irradiation of the inner content and surrounding wall; (2) 'Void': irradiation of a void part of the bottle without the filling material (e.g., practically only the wall material); and (3) 'Plug': irradiation of the cork region and surrounding walls. Since the geometry of the investigated sample is indefinite and the efficiency and selfabsorption corrections are uncertain, absolute
Fig. 8 Neutron CT. a Global front view obtained from a set of nine partial front views. Red markers indicate the illumination areas by prompt gamma activation imaging (PGAI), related to Table 1 . b Front views in the region of the mobile content for three positions of the pottery: rotation by $0^{\circ}, 30^{\circ}$ and $60^{\circ}$ around the vertical axis. Online Resource 3 shows a $3 \mathrm{D}$ video representing the object fixed in another position and under four different projection angles $\left(0,30^{\circ}, 60^{\circ}\right.$, $90^{\circ}$ )

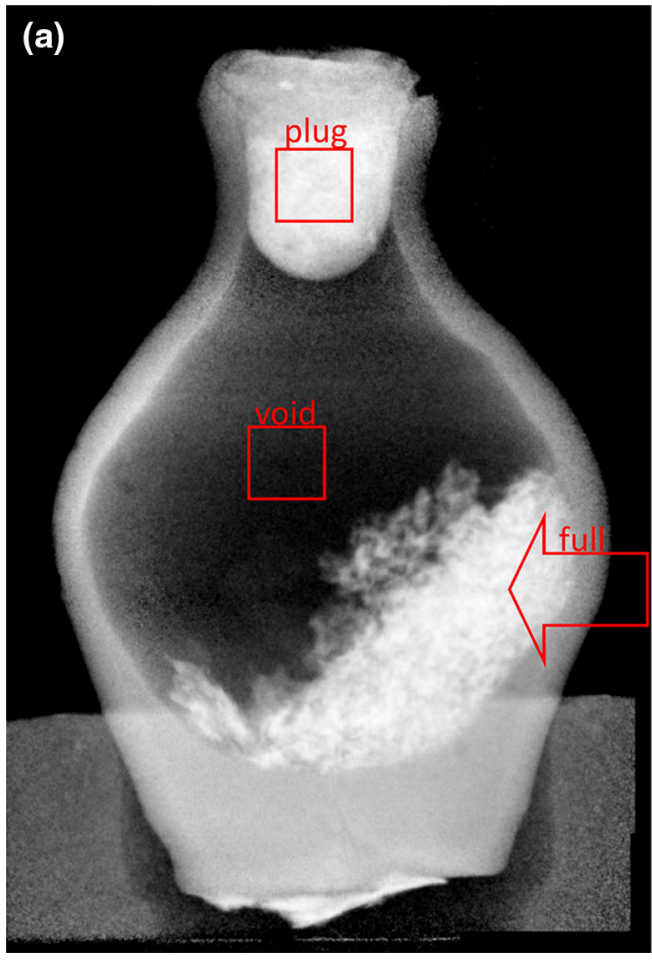

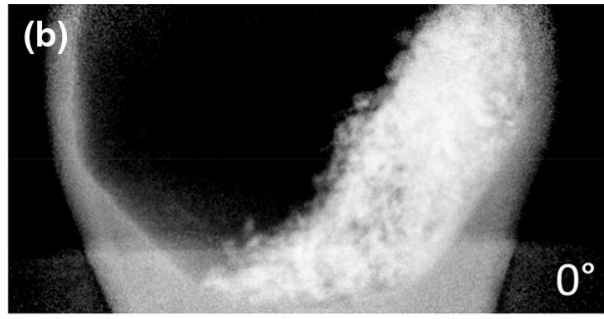
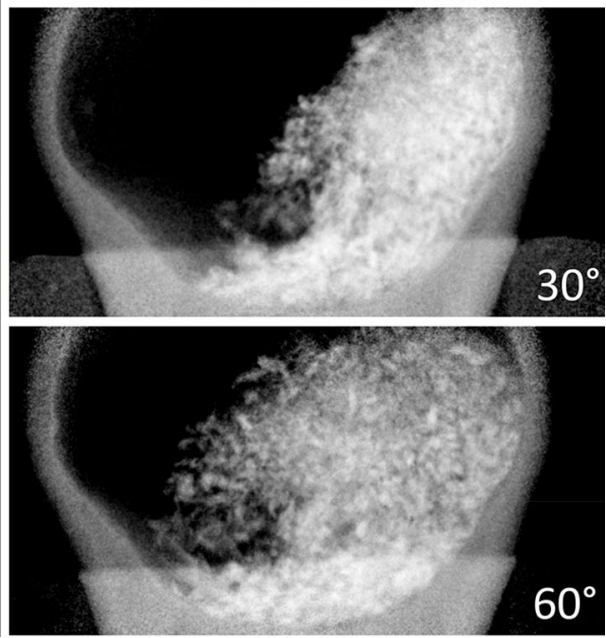
Fig. 9 Neutron CT. Analysis of the cork. a 3D representation of the cork obtained with a volume rendering software. b Axial views at the position 1 and 2 indicated in (a). Online Resource 4 is a $3 \mathrm{D}$ video of the cork using neutron CT
Table 1 Elemental composition determined by prompt gamma activation imaging (PGAI): elemental concentration in weight $\%$ and uncertainty
$<$ D.L. means under detection limit. Illumination areas are indicated in Fig. 8a by the red markers. 'Full': irradiation of the inner content and surrounding wall. 'Void': irradiation of the empty part of the bottle without the filling material. 'Plug': irradiation of the cork region and surrounding walls
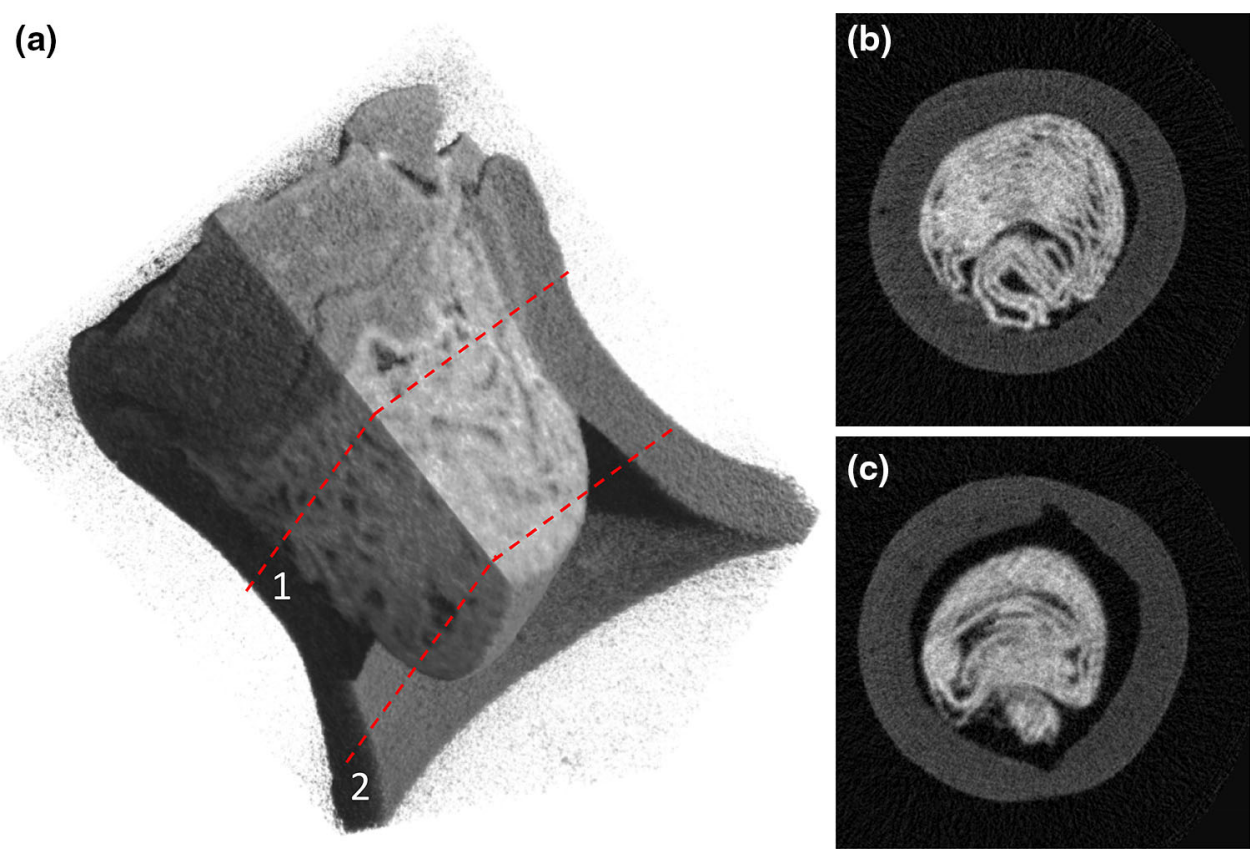

\begin{tabular}{|c|c|c|c|c|c|c|c|c|}
\hline \multicolumn{3}{|l|}{ Full } & \multicolumn{3}{|l|}{ Void } & \multicolumn{3}{|l|}{ Plug } \\
\hline Element & $\begin{array}{l}\text { Weight } \\
\%\end{array}$ & $\begin{array}{l}\text { Rel. Unc. } \\
\%\end{array}$ & Element & $\begin{array}{l}\text { Weight } \\
\%\end{array}$ & $\begin{array}{l}\text { Rel. Unc. } \\
\%\end{array}$ & Element & $\begin{array}{l}\text { Weight } \\
\%\end{array}$ & $\begin{array}{l}\text { Rel. Unc. } \\
\%\end{array}$ \\
\hline $\mathrm{H}$ & 1.3 & 8 & $\mathrm{H}$ & 0.4 & 11 & $\mathrm{H}$ & 1.4 & 6 \\
\hline B & 0.0015 & 8 & B & 0.0016 & 11 & B & 0.0012 & 6 \\
\hline $\mathrm{C}$ & 8.0 & 11 & $\mathrm{C}$ & $<D . L$. & & $\mathrm{C}$ & 16.1 & 8 \\
\hline $\mathrm{N}$ & 0.85 & 10 & $\mathrm{~N}$ & $<D . L$. & & $\mathrm{N}$ & 0.18 & 23 \\
\hline $\mathrm{O}$ & 60.0 & 5 & $\mathrm{O}$ & 61.0 & 7 & $\mathrm{O}$ & 52.6 & 6 \\
\hline $\mathrm{Na}$ & 0.89 & 8 & $\mathrm{Na}$ & 1.24 & 11 & $\mathrm{Na}$ & 0.95 & 7 \\
\hline $\mathrm{Mg}$ & 1.3 & 9 & $\mathrm{Mg}$ & 1.6 & 14 & $\mathrm{Mg}$ & 1.2 & 8 \\
\hline $\mathrm{Al}$ & 5.4 & 8 & $\mathrm{Al}$ & 6.3 & 11 & Al & 4.5 & 7 \\
\hline $\mathrm{Si}$ & 14.4 & 8 & $\mathrm{Si}$ & 19.5 & 11 & $\mathrm{Si}$ & 13.2 & 6 \\
\hline S & 0.046 & 23 & $\mathrm{~S}$ & $<D . L$. & & $\mathrm{S}$ & 0.14 & 8 \\
\hline CI & 0.058 & 8 & CI & 0.033 & 11 & CI & 0.18 & 6 \\
\hline K & 0.93 & 8 & $\mathrm{~K}$ & 1.05 & 11 & K & 0.66 & 6 \\
\hline $\mathrm{Ca}$ & 2.2 & 9 & $\mathrm{Ca}$ & 2.3 & 11 & $\mathrm{Ca}$ & 4.5 & 7 \\
\hline $\mathrm{Sc}$ & 0.0011 & 8 & $\mathrm{Sc}$ & 0.0006 & 17 & $\mathrm{Sc}$ & 0.0007 & 7 \\
\hline $\mathrm{Ti}$ & 0.61 & 8 & $\mathrm{Ti}$ & 0.82 & 11 & $\mathrm{Ti}$ & 0.56 & 7 \\
\hline V & 0.0082 & 15 & V & 0.016 & 13 & V & 0.012 & 10 \\
\hline $\mathrm{Cr}$ & 0.039 & 24 & $\mathrm{Cr}$ & 0.042 & 16 & $\mathrm{Cr}$ & 0.017 & 10 \\
\hline $\mathrm{Mn}$ & 0.071 & 8 & $\mathrm{Mn}$ & 0.098 & 11 & $\mathrm{Mn}$ & 0.065 & 7 \\
\hline $\mathrm{Fe}$ & 4.0 & 8 & $\mathrm{Fe}$ & 5.6 & 11 & $\mathrm{Fe}$ & 3.6 & 7 \\
\hline $\mathrm{Nd}$ & 0.0024 & 15 & $\mathrm{Nd}$ & 0.0032 & 14 & $\mathrm{Nd}$ & 0.0024 & 11 \\
\hline $\mathrm{Sm}$ & 0.00042 & 8 & $\mathrm{Sm}$ & 0.00056 & 11 & $\mathrm{Sm}$ & 0.00034 & 7 \\
\hline $\mathrm{Gd}$ & 0.00032 & 10 & $\mathrm{Gd}$ & 0.00046 & 13 & $\mathrm{Gd}$ & 0.00028 & 9 \\
\hline
\end{tabular}

concentrations of the identified components were not given. Instead, we present approximate elemental composition for the inner content. One can see that characteristic elements for ceramics (Na, Mg, Al, Si, K, Ca, Ti, Mn and Fe) are roughly in the same amounts in both 'Full' and 'Void' measurements, confirming the correctness of this approach. On the other hand, some elements characteristic to organic material (H, C, N, S and Cl) show an excess in case of 'Full' 
measurement, compared with 'Void' one. Furthermore, composition of the plug shows an excess of $\mathrm{H}, \mathrm{C}, \mathrm{N}, \mathrm{S}, \mathrm{Cl}$ too, that confirms the organic nature of the string.

As a result, we can finally assume that the content could consist of germinated seeds (or any other dried organic material) such as barley that was a staple cereal of ancient Egypt. We also concluded that the internal cork could be made of a ball of linen. Further investigation should consist in characterizing the molecular composition of these materials using a portable $\mathrm{THz}$ spectrometer in order to avoid the transportation of the fragile object and the use of a huge and costly instrument such as nuclear reactor.

\section{Conclusion}

For the first time, THz, X-ray and neutron imaging have been complementarily applied to provide a better understanding of an art-related object. Our attention has been focused on an Eighteenth Dynasty Egyptian sealed pottery stored at the Museum of Aquitaine (Bordeaux, France). We pointed out that the main advantage of $\mathrm{THz}$ radiation is the possibility of rapid and rather cheap on-site nondestructive and noninvasive diagnosis, even if it is limited by a millimeter spatial resolution. This first investigation brings out very interesting elements leading the curators to go further into the analysis with more complex and expensive experimental techniques. In our case, the main feature highlighted by $\mathrm{THz}$ radiation is the presence of a mobile and deformable content whose composition remains unknown owing to the incapacity of our system to perform spectroscopic measurements. However, spectral information could be obtained using a portable broadband $\mathrm{THz}$ source. X-rays revealed the presence of many cracks and damages, thus giving more information for the curators about the conservation state of the pottery. X-rays also provide a clearer representation of the content and the presence of an internal cork with lighter density compared with clay. Finally, neutron imaging informed about the way the object has been closed by a double stopper (clay and probably a ball of linen or any other string-like organic material) and provided a more accurate representation of the mobile and heterogeneous content, probably constituted of germinated seeds. These partial conclusions emphasize the complementarity and specificity of $\mathrm{THz}, \mathrm{X}$-ray and neutron imaging that may be of a prime importance for historians and museum curators in order to enlarge the understanding of our cultural heritage.

Acknowledgments The authors gratefully acknowledge François Hubert, director of the Museum of Aquitaine, and the city of Bor deaux for the authorization to perform the measurements at the museum. They also thank R. Trouette, M. Montaudon and J.B. Boutolleau from the radiotherapy centre at the Haut Lévêque Hospital
(Bordeaux) for X ray measurements, P. Decout and T. Solaire from General Electric Healthcare for the $\mathrm{X}$ ray data reconstruction. This project has been supported by the CHARISMA project (Contract 228330) and the Action Interdisciplinaire de Recherche 'Arch éométrie' (TeraScan project, CNRS, France).

\section{References}

1. J. Banhart John (Ed.) Advanced tomographic methods in mate rials research and engineering (Oxford University Press, ISBN 978019921324 5, 2008)

2. C. Calza, M.J. Anjos, S.M.F. Mendonça de Souza, A. Branca glion Jr, R.T. Lopes, Nucl. Instr. Meth. B 263, 249252 (2007)

3. O. Hahn, Stud. Conserv. 50, 23 (2005)

4. M.J. Aitken, Thermoluminescence Dating (Academic Press, London, 1985)

5. I.A. Anderson, R.L. McGreevy, H.Z. Bilheux (Eds), Neutron imaging and applications: a reference for the imaging community (Springer, ISBN 978038778692 6, 2009)

6. E. Deschler Erb, E.H. Lehmann, L. Pernet, P. Vontobel, S. Hartmann, Archaeometry 46(4), 647 (2004)

7. E.H. Lehmann, S. Hartmann, M.O. Speidel, Archaeometry 52(3), $416(2010)$

8. J.B. Jackson, J. Bowen, G. Walker, J. Labaune, G. Mourou, M. Menu, K. Fukunaga, IEEE Trans. Terahertz. Sci. Technol. 1(1), $220(2011)$

9. L. Ohrström, A. Bitzer, M. Walther, F.J. Rühli, Am. J. Phys. Anthropol. 142(3), 497 (2010)

10. J. Labaune, J.B. Jackson, S. Pagès Camagna, I.N. Duling, M. Menu, G.A. Mourou, Appl. Phys. A 100(3), 607 (2010)

11. J. Labaune, J.B. Jackson, K. Fukunaga, J. White, L. D' Ales sandro, A. Whyte, M. Menu, G.A. Mourou, Appl. Phys. A 105(1), 5 (2011)

12. K. Fukunaga, E. Cortes, A. Cosentino, I. Stünkel, M. Leona, I.N. Duling III, D.T. Mininberg, J. Eur. Opt. Soc. Rapid Commun. 6, 11040 (2011)

13. F. Saragoza, Revue archéologique de Bordeaux, tome IC, p.131 (French) (2008)

14. M. Bessou, H. Duday, J. P. Caumes, S. Salort, B. Chassagne, A. Dautant, A. Ziéglé, E. Abraham, Opt. Commun. 285, 4175 (2012)

15. G.N. Hounsfield, J. Comput. Assist. Tomogr. 4, 665 (1980)

16. N. Kardjilov, Sci. Rev. 11(1), 15 (2006)

17. K. Kawase, Y. Ogawa, Y. Watanabe, H. Inoue, Opt. Express 11, 2549 (2003)

18. B. Recur, A. Younus, S. Salort, P. Mounaix, B. Chassagne, P. Desbarats, J. P. Caumes, E. Abraham, Opt. Express 19, 5105 (2011)

19. B. Ferguson, S. Wang, D. Gray, D. Abbot, X.C. Zhang, Opt. Lett. 27, $1312(2002)$

20. A. Brahm, M. Kunz, S. Riehemann, G. Notni, A. Tunnermann, Appl. Phys. B 100, 151 (2010)

21. G.T. Herman, image reconstruction from projections: the funda mentals of computerized tomography (Academic Press Inc., 1980)

22. M.P. Morigi, F. Casali, M. Bettuzzi, R. Brancaccio, V.D. Errico, Appl. Phys. A 100, 653 (2010)

23. www.gehealthcare.com

24. L. Szentmiklósi, Z. Kis, T. Belgya, Zs. Révays, Prompt gamma activation imaging at the Budapest research reactor, in Report of the IAEA F1 TM 40776 Catalogue of Products and Services of Research Reactors: Applications of Neutron Beams 57 Sep tember 2011, IAEA, Vienna, Austria (ed. D. Ridikas)

25. www.advancedphotonix.com/thzsolutions/, www.teraview.com/ 